\title{
Circular economy: barrier and opportunities for SMEs
}

\author{
Ni Putu Santi Suryantini ${ }^{1}$, I Wayan Edi Arsawan ${ }^{2, *}$, Ni Putu Ayu Darmayanti ${ }^{3}$, Svitlana \\ Moskalenko ${ }^{4}$, and Tetiana Gorokhova ${ }^{5}$ \\ ${ }^{1,3}$ Universitas Udayana, Faculty of Economics and Business, 80112 Bali, Indonesia \\ ${ }^{2}$ Politeknik Negeri Bali, Department of Business Administration, 80364 Bali, Indonesia \\ ${ }^{4}$ National Academy of Public Administration under the President of Ukraine, 20, Antona Tsedika str., \\ 03057, Kyiv, Ukraine \\ ${ }^{5}$ Pryazovskyi State Technical University, 7 Universytetska st., 87555 Mariupol, Ukraine
}

\begin{abstract}
The circular economy was a concept introduced by the European Union consortium, several national governments, and business people around the world. However, the scientific and research content of the circular economy concept is so superficial and disorganized that it is still a vague collection of ideas separate from several fields of science. The purpose of this study is to measure visual trends in the circular economy. This survey identified keywords related to the circular economy to find and identify related articles in the Scopus database for 1000 articles published from 2000 to 2021 . The findings were a visual trend of the increasing number of publications each year, academic affiliation, author, article subject area, keywords, and authorship network. This literature review provides evidence that circular economy thinking attracts academic researchers to formulate relevant policies.
\end{abstract}

\section{Introduction}

Responding to human activities that cause environmental degradation at various levels, it is necessary to make comprehensive changes in production and consumption patterns [1]. In particular, it is necessary to start shifting from a linear "take, make, use and waste" production-consumption model to a circular model that minimizes, recovers, recycles, and reuses materials, water, and energy [2-3]. The circular economy concept describes a circular production-consumption model that maximizes the use of products, components, and materials throughout their life cycle [3]. This is a means of reducing environmental impacts while promoting economic growth [4].

Transition to circular economy requires commitment from many parties, including the government and the companies themselves [5]. In particular, circular economy requires companies to develop and adopt innovative technologies and business models [6] as part of a more circular economy -oriented organizational culture [7]. This can lead to new 'circular risks' due to the company's transition from the tried and tested linear production method to the new circular production method [8]. Limited resources for SMEs lead to potential

*Corresponding author: wayanediarsawan@pnb.ac.id 
impediments to circular economy implementation [9-10] although SMEs have an important contribution to a country's economic and social development [11].

To bridge the research mechanism of circular economy from the perspective of individuals, organizations, and the environment, the role of government, practitioners, and decision-makers is very important. The involvement of SMEs in achieving circular economy goals is very clear because they have a production line that can carry out the circular economy process holistically both from inputs, processes, outputs, and outcomes that are friendly to the environment, especially through a culture of innovation at the organizational and employee levels [12]. Despite receiving, until now, the role of SMEs in circular economy succession is still very rare [13] therefore it is necessary to map the literature to generate opportunities and potential for $\mathrm{R} \& \mathrm{D}$ through collaborative global writers networks.

On the other hand, although the topic of the circular economy has increased from year to year, there are still many unanswered matters, it has not been explored optimally because the circular economy concept has several limitations [14]. This study offers an extensive literature review and aims to highlight research outputs and trends in a circular economy to increase the amount of research and the need for interdisciplinary collaboration to increase the importance of global understanding [15] such as the increasing awareness of humans about lifestyle changes to focus more on nature and the concept of green [16]. research that focuses on circular economy focuses primarily on small samples, or single case studies, or literature reviews without visualization. To our knowledge, no study has presented a big picture and visualization of research trends concerning circular economy. To that end, we used VOSviewer [17] to map an extensive literature review and survey of 1000 articles on circular economy published and indexed by the Scopus database 2021. This means that the important contribution of circular economy research to science can be calculated by the quantity and quality of publications and citations from various perspectives, thereby increasing the authorship network which is useful for exploring scientific collaboration between researchers around the world.

\section{Material and Methods}

To obtain the final visualization with the help of VOSViewer [17], we identified peerreviewed articles on the Scopus bibliography - as one indexer with a comprehensive database - in particular Elsevier and ScienceDirect. We identified the keywords "circular economy" and "SMEs" resulting in 1000 articles which we downloaded in the form of a research information system (* ris) and then transferred to Mendeley. This research was carried out in the range of January-February 2021 by identifying keywords that were used to find information related to circular economy.

From these 1000 articles, we feed them to VOSViewer and other open-source applications to analyze the corpus of text from the RIS databases. The reason for choosing VOSViewer is its function in making publication maps, journal maps and country maps, citation and keyword maps [17]. Besides that, VOSViewer is also used for data mining, articles. grouping, and mapping on various database sources [18].

\section{Result}

In general, the number of published articles about circular economy in the SME sector that are published on the Scopus database is increasing every year. The highest peak of publication occurred in 2019, but decreased in 2017 and increased again the following year. The growth and evolution of research on circular economy can be "measured" as well by a 
great discussion about the increasingly familiar concept of sustainable development and the increasingly massive publications on circular economy in various sectors of life.

To analyze data with the help of VOSViewer, this study uses the minimum number of relationships with terms to be 10 terms. After being analyzed, there are 8 clusters (gray, red, pink, green, light green, blue, light blue, and yellow) that show the relationship and complexity between one topic and another. VOSViewer can display bibliometric mapping in three different visualizations namely network visualization (Figure 1), overlay visualization (Figure 2), and density visualization (Figure 3). Keywords are labeled with colored circles. Article size is positively correlated with the occurrence of keywords in titles and abstracts. Therefore, the size of letters and circles is determined by the frequency with which they appear. The more often the keyword appears, the larger the font and circle size.

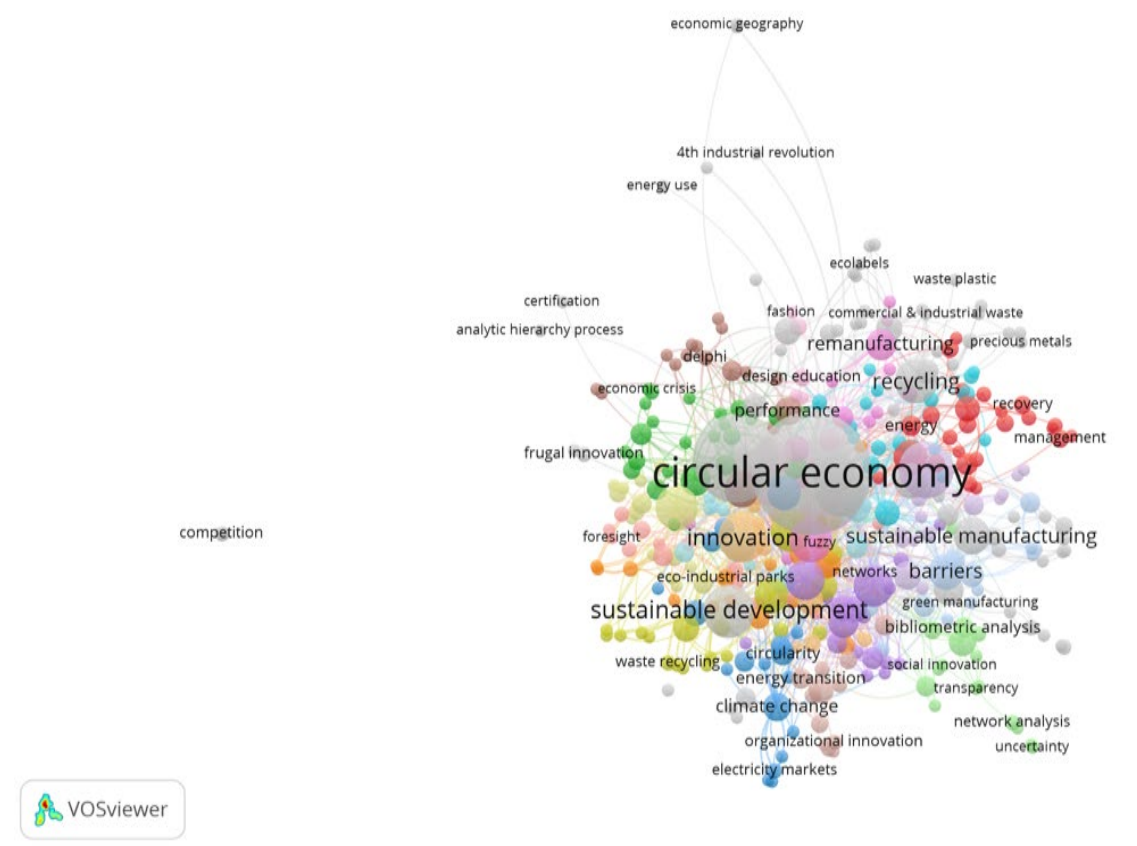

Fig. 1. Visualization Topic area using Network Visualization.

Extraction of titles, keywords, and abstract obtained 1000 documents consisting of 3142 authors. The data consisted of two types of publications, namely research papers (912) and literature reviews (88). Figure 1 shows the clusters of each of the topic areas studied. It can be seen that the keywords "circular economy" are in the largest cluster, followed by "sustainable development", "innovation" and "recycling" which indicate a close relationship between these keywords. 


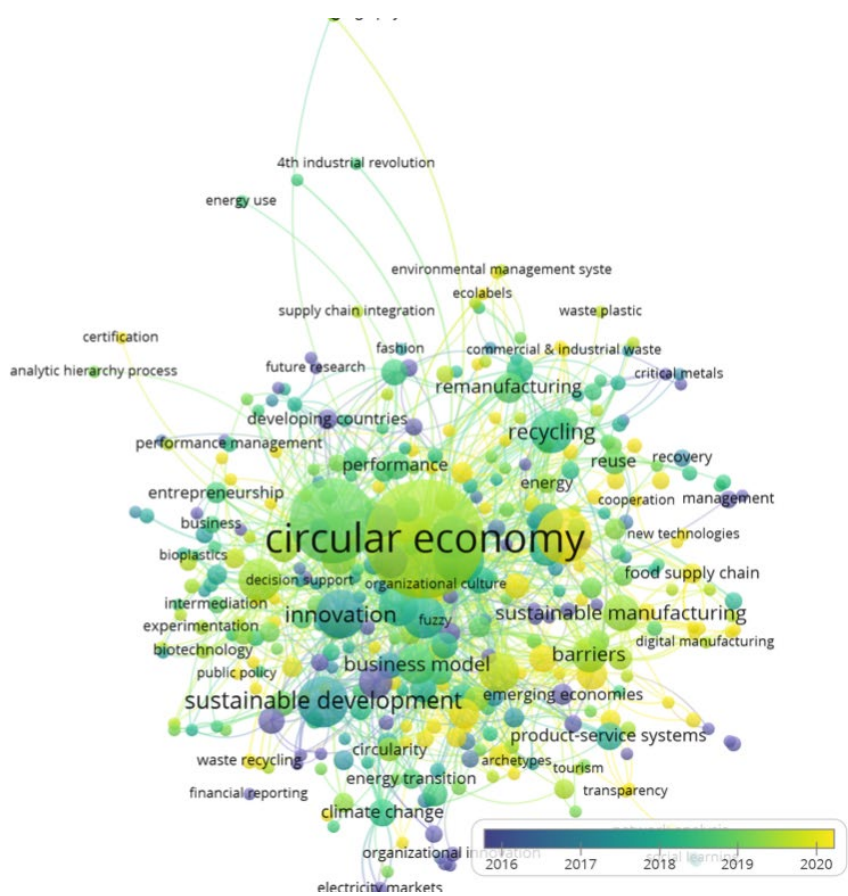

Fig. 2. Visualization Topic area using Overlay Visualization.

Meanwhile, Figure 2 shows the trend from year to year related to this research. In 2016 there was more research on business models and cooperation management, in 2017 on climate change, innovation, and recycling, in 2018 on performance, while in 2019 the focus was on research on sustainable manufacturing and several other studies (such as barriers, food supply chain, circularity), the latest research in 2020 is to focus on organizational learning to support a circular economy [19-23].

The analysis that will be carried out on the topic of "business models" to create "sustainable development" is to reduce "barriers" which can be seen from the amount of research that has been done. From Figure 2 it is presented that recycling and business models show relatively small numbers compared to sustainable manufacturing and sustainable development [24-30]. This means that there is a great opportunity to research sustainable development as part of the impact of circular economy [19] through the use of green technology [20], individual and organizational innovation [21], to reduce various barriers in it [22, 31-34].

Furthermore, to measure the depth of research on circular economy in SMEs, (see Figure 3), it is shown by the colour texture, where the darker the colour appears, the more research will be done. The conclusion from Figure 1-3 shows that the keywords that often appear are "circular economy", "innovation" and "sustainable development". From these data, we can look for new circular economy research, especially in the SME sector. For example, research related to the process of "recycling", "performance management" and "organizational innovation" is because is still little researched.

For this reason, further researchers can contribute to increasing insights about circular economy by conducting studies on the use of "new technologies", "building organizational culture" in "reuse", "recycle" and "waste management" [23]. Besides, the availability of information on each topic area can be searched by entering more specific keywords. 


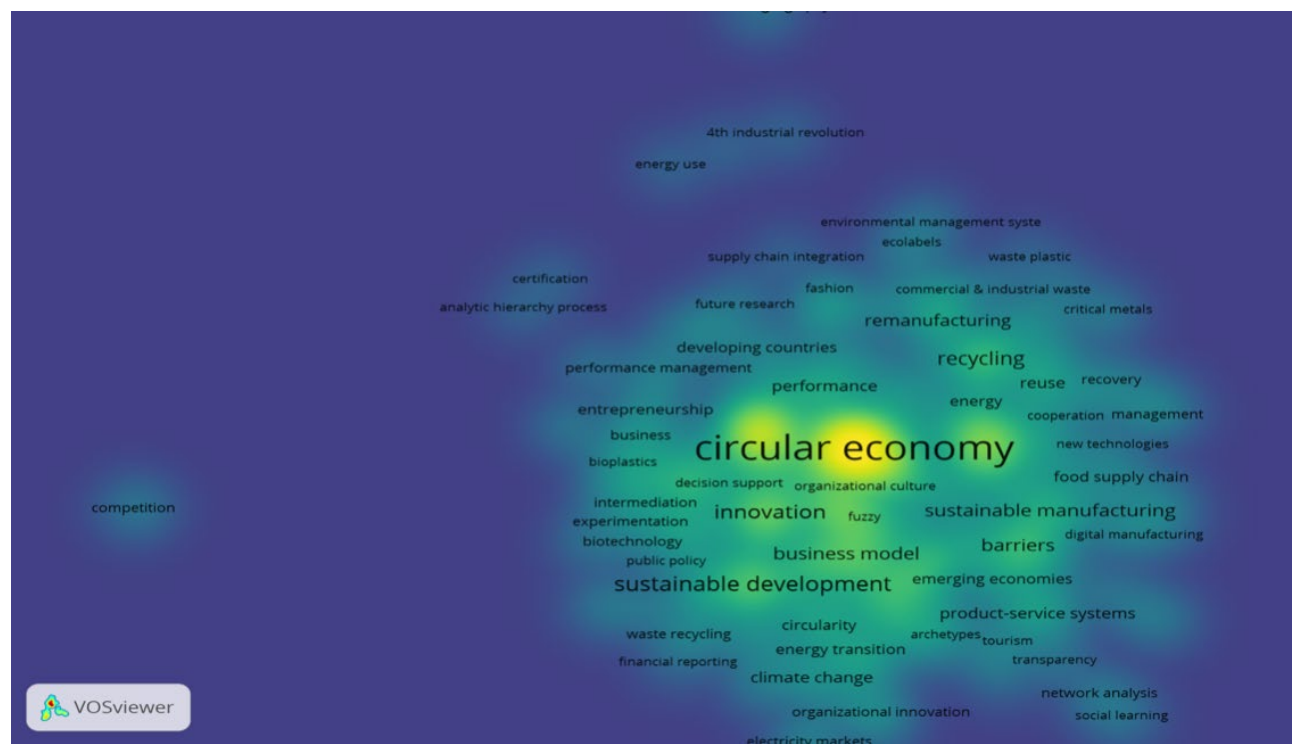

Fig. 3. Visualization Topic area using Density Visualization.

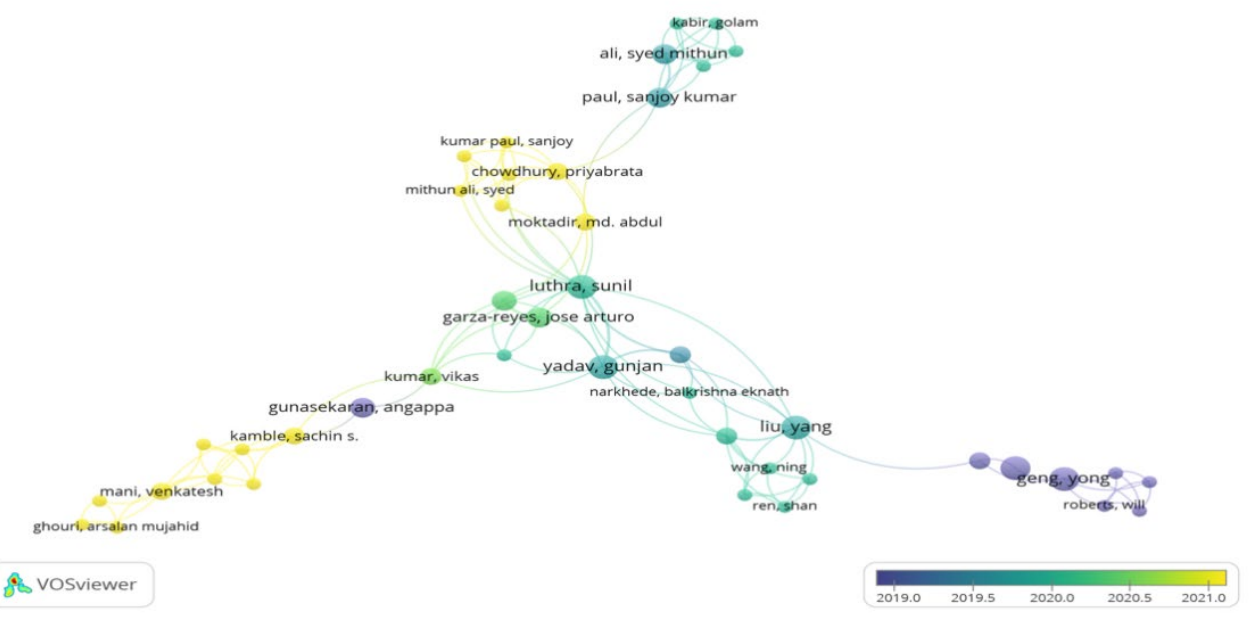

Fig. 4. Networking based on authorships.

Next, we look at six collaborative groups among authors in the circular economy field as shown in Figure 4, namely the first group (i.e.: (Kabir and Golam); (Ali and Syed Mithun); (Paul and Sanjoy Kumar); the second group (Kumar), Pail and Sanjoy); (Chowdury and Priyabrata); (Mithun and Ali Syed); (Moktadir and Md. Abdul), the third group (Lutra and Sunil); (Garza-reyes and Jose Arturo); (Yadav and Gunjan); (Kumar and Vikas); (Gunasekaran and Angappa) fourth group (Kamble and Sachin S); (Mani and Venkatesh): Ghoury, Arsalan, Mujahid) the fifth group (Narkhede, Balkrishna Eknath); (Liu and Yang); (Wang and Ning); (Ren and Shan) and the sixth group (Geng and Yong); (Roberts and Will). Collaboration among researchers in the circular economy field will increase the number and quality of publications and citation opportunities. 


\section{Conclusions}

This study aims to measure the visual trend in the circular economy, especially in the SME sector. The findings of this literature review provide evidence that circular economy thinking attracts academic researchers through the visualization of related topics but we still find many opportunities to explore future research. This research has limited objectives, tools, and data sources. The study attempts to investigate visual and network trends in the circular economy field. However, the study did not measure the contribution and impact of the research in terms of citations. This is because VosViewer as a research tool is not designed to analyze citations. The analysis in this paper is based solely on the Scopus dataset, while there are more relevant papers not indexed by Scopus, especially those written in local (non-English) languages. For this reason, the next research is to analyze the contribution and impact of the research by measuring citations based on a combination of Scopus, WoS data, and other database sources.

\section{References}

1. Doyle, A. (2019). The heat is on: Taking stock of global climate ambition. In NDC Global Outlook Report, United Nations Development Programme and United Nations Framework Convention on Climate Change.

2. Geissdoerfer, M., Savaget, P., Bocken, N. M., \& Hultink, E. J. (2017). The Circular Economy-A new sustainability paradigm? Journal of cleaner production, 143, 757-768.

3. Kirchherr, J., Piscicelli, L., Bour, R., Kostense-Smit, E., Muller, J., HuibrechtseTruijens, A., \& Hekkert, M. (2018). Barriers to the circular economy: evidence from the European Union (EU). Ecological Economics, 150, 264-272.

4. Millar, N., McLaughlin, E., \& Börger, T. (2019). The circular economy: swings and roundabouts? Ecological economics, 158, 11-19.

5. Diercks, G., Larsen, H., \& Steward, F. (2019). Transformative innovation policy: Addressing variety in an emerging policy paradigm. Research Policy, 48(4), 880-894.

6. Bocken, N. M., De Pauw, I., Bakker, C., \& Van Der Grinten, B. (2016). Product design and business model strategies for a circular economy. Journal of Industrial and Production Engineering, 33(5), 308-320.

7. Ghisellini, P., \& Ulgiati, S. (2020). Circular economy transition in Italy. Achievements, perspectives and constraints. Journal of Cleaner Production, 243, 118360 .

8. Ghisetti, C., \& Montresor, S. (2020). On the adoption of circular economy practices by small and medium-size enterprises (SMEs): does "financing-as-usual" still matter?. Journal of Evolutionary Economics, 30(2), 559-586.

9. Ormazabal, M., Prieto-Sandoval, V., Puga-Leal, R., \& Jaca, C. (2018). Circular economy in Spanish SMEs: challenges and opportunities. Journal of Cleaner Production, 185, 157-167.

10. Rizos, V., Behrens, A., Van der Gaast, W., Hofman, E., Ioannou, A., Kafyeke, T., ... \& Topi, C. (2016). Implementation of circular economy business models by small and medium-sized enterprises (SMEs): Barriers and enablers. Sustainability, 8(11), 1212.

11. OECD, S., \& Outlook, E. (2019). Policy Highlights.

12. Arsawan, I. W. E., Koval, V., Rajiani, I., Rustiarini, N. W., Supartha, W. G., \& Suryantini, N. P. S. (2020). Leveraging knowledge sharing and innovation culture into 
SMEs sustainable competitive advantage. International Journal of Productivity and Performance Management.

13. Garrido-Prada, P., Lenihan, H., Doran, J., Rammer, C., \& Perez-Alaniz, M. (2021). Driving the circular economy through public environmental and energy R\&D: Evidence from SMEs in the European Union. Ecological Economics, 182, 106884.

14. Korhonen, J., Honkasalo, A., \& Seppälä, J. (2018). Circular economy: the concept and its limitations. Ecological economics, 143, 37-46.

15. Murray, A., Skene, K., \& Haynes, K. (2017). The circular economy: an interdisciplinary exploration of the concept and application in a global context. Journal of business ethics, 140(3), 369-380.

16. Schröder, P., Lemille, A., \& Desmond, P. (2020). Making the circular economy work for human development. Resources, Conservation and Recycling, 156, 104686.

17. Van Eck, N. J., \& Waltman, L. (2010). Software survey: VOSviewer, a computer program for bibliometric mapping. scientometrics, 84(2), 523-538.

18. Xie, L., Chen, Z., Wang, H., Zheng, C., \& Jiang, J. (2020). Bibliometric and visualized analysis of scientific publications on atlantoaxial spine surgery based on Web of Science and VOSviewer. World Neurosurgery, 137, 435-442.

19. El Wali, M., Golroudbary, S. R., \& Kraslawski, A. (2021). Circular economy for phosphorus supply chain and its impact on social sustainable development goals. Science of The Total Environment, 777, 146060.

20. Isa, N. M., Sivapathy, A., \& Kamarruddin, N. N. A. (2021). Malaysia on the Way to Sustainable Development: Circular Economy and Green Technologies. In Modeling Economic Growth in Contemporary Malaysia. Emerald Publishing Limited.

21. Arsawan, I., Wirga, I. W., Rajiani, I., \& Suryantini, N. P. S. (2020). Harnessing knowledge sharing practice to enhance innovative work behavior: the paradox of social exchange theory. Polish Journal of Management Studies, 21.

22. Grafström, J., \& Aasma, S. (2021). Breaking circular economy barriers. Journal of Cleaner Production, 126002.

23. Koval, V., Mikhno, I., Trokhymets, O., Kustrich, L., Vdovenko, N. (2020). Modeling the interaction between environment and the economy considering the impact on $\begin{array}{llll}\text { ecosystem. } & \text { E3S } & \text { Web }\end{array}$ https://doi.org/10.1051/e3sconf/202016613002

24. Koval, V., Mikhno, I., Hajduga, G. \& Gaska, K. (2019). Economic efficiency of biogas generation from food product waste. E3S Web Conference, 100, 00039.

https://doi.org/10.1051/e3sconf/201910000039

25. Mikhno, I., Koval, V., Shvets, G., Garmatiuk, O., \& Tamošiūnienė, R. (2021). Green Economy in Sustainable Development and Improvement of Resource Efficiency. Central European Business Review, 10(1), 99-113. https://doi.org/10.18267/j.cebr.252

26. Shmygol N., Galtsova O., Solovyov O., Koval V., Arsawan I. (2020). Analysis of country's competitiveness factors based on inter-state rating comparisons. E3S Web Conferences, 153, 03001. https://doi.org//10.1051/e3sconf/202015303001

27. Koval, V., Kovshun, N., Plekhanova, O., Kvitka, S., \& Haran, O. (2019). The role of interactive marketing in agricultural investment attraction. SGEM 2019, 19(5.3), 877884. https://doi.org/10.5593/sgem2019/5.3/S21.111

28. Hutsaliuk, O., Koval, V., Tsimoshynska, O., Koval, M., Skyba, H. (2020). Risk Management of Forming Enterprises Integration Corporate Strategy. TEM Journal, 9(4), 1514-1523. https://doi.org/10.18421/TEM94-26 
29. Shmygol, N., Schiavone, F., Trokhymets, O., Pawliszczy, D., Koval, V., Zavgorodniy, R., Vorfolomeiev A. (2020). Model for assessing and implementing resource-efficient strategy of industry. CEUR Workshop Proceedings, 2713, 277-294.

30. Dankeieva, O., Solomianiuk, N., Strashynska, L., Fiedotova, N., Soloviova, Y., \& Koval, V. (2021). Application of Cognitive Modelling for Operation Improvement of Retail Chain Management System. TEM Journal, 10(1), 358-367. https://doi.org/10.18421/TEM101-45

31. Mykytenko, V.V., \& Lytsur, I.M. (2020). Threats and risks of implementation of the spatial model of natural resource management. Balanced nature management, 1, 11-20. https://doi.org/10.33730/2310-4678.1.2020.203916

32. Prokopenko, O.V., \& Shkola, V.Y. (2012). Controlling of the ecological and economic enterprise security on the bases of ecomarketing. Marketing and Management of Innovation, 4, 337-346.

33. Atstaja, D., Uvarova, I., Kambala, D. K., Alberte, V., Stokmane, K., GegereZetterstroma, A., ... \& Zapletnuka, G. (2020). Investments to Develop Business Models and Projects in the Circular Economy. In IOP Conference Series: Earth and Environmental Science, 578(1), 012029.

34. Pogodayev, S. E. (2013). Marketing of works as a source of the new hybrid offerings in widened marketing of goods, works and services. Journal of Business \& Industrial Marketing, 28(8), 638-648. https://doi.org/10.1108/jbim-04-2012-0069 